\title{
0 cálculo do presidente ao nomear ministros no Brasil
}

\section{Pedro Neiva 1}

Taeko Hiroi 2

1 Universidade de Brasília / Departamento de Administração, Brasília / DF - Brasil

2 The University of Texas at El Paso / Department of Political Science, El Paso / TX - Estados Unidos da América

Este artigo procura identificar os fatores que influenciam a escolha dos ministros no Brasil, considerando a importância/saliência de cada um dos ministérios. Buscamos conhecer a influência dos aspectos regionais sobre tal escolha, controlando as características e trajetórias pessoais dos ministros, seja no que diz respeito aos aspectos políticos e técnicos, seja com relação à proximidade e à lealdade ao presidente da República. Para isso, utilizamos um banco de dados inédito, que abrange todo o período da Nova República.

Palavras-chave: presidencialismo de coalizão; ministérios; governo; elites políticas; gabinete.

\section{El cálculo presidencial en el nombramiento de ministros en Brasil}

Este artículo busca identificar los factores que influyen la selección de ministros en Brasil, considerando la importancia y protagonismo de cada uno de los ministerios. Buscamos identificar la influencia de los aspectos regionales en esta selección, controlando las características y trayectorias personales de los ministros, ya sea en lo que respecta a aspectos políticos y técnicos o a la proximidad y lealtad al presidente de la República. Para ello, utilizamos una base de datos inédita, que cubre todo el período de la Nueva República.

Palabras clave: presidencialismo de coalición; ministerios; gobierno; élites políticas; gabinete.

\section{The presidential calculous in the appointment of ministers in Brazil}

This article aims to identify the factors that influence the selection of ministers in Brazil, considering the number of portfolios and their importance and saliency. We identify the regional influence on such selection, controlling for ministers' personal characteristics and trajectories, including political aspects, expertise, and proximity, and loyalty to the president. We use an original dataset that covers the entire period known as the New Republic. Keywords: coalitional presidentialism; ministries; government; political elite; cabinet. 


\section{INTRODUÇÃO}

Este artigo procura contribuir para a discussão sobre a influência das forças políticas regionais na formação do governo central no Brasil. Em outras palavras, pretendemos avaliar o impacto dos fatores regionais nas escolhas dos ministros. Queremos saber se há alguma relação entre a importância política do ministério e a origem (ou ligação) regional do ministro. Nossa hipótese é a de que os ministros oriundos das regiões ricas, especialmente do Sudeste e do estado de São Paulo, tendem a ocupar os ministérios mais cobiçados pelos políticos.

Além do debate sobre as regiões, buscamos dar outras contribuições. Uma delas é considerar a relevância política dos ministérios nesse contexto. Até então, a grande maioria das pesquisas considerou apenas o número de ministérios, como se eles fossem todos iguais. Sabemos que não é o que acontece no mundo real (Abranches, 1988; Amorim, 2000).

Batista (2018) e Mauerber e Pereira (2020) são exceções, já que consideraram o grau de atratividade dos ministérios com base em seus orçamentos, capacidade regulatória, distribuição de cargos ou patronagem. Porém, o enfoque dado por esses autores é diferente do nosso. Eles não centram a atenção sobre o recrutamento do ministro em si e não consideram os fatores regionais, as características pessoais e outros aspectos que podem motivar a escolha do presidente. Estão preocupados com a distribuição dos ministérios entre os partidos, o grau de coalescência da coalizão ou as possíveis consequências sobre os resultados no Legislativo. Neste estudo, os atributos dos ministérios aparecem como variável dependente, enquanto nos dos autores citados estão mais para variáveis explicativas.

Outra contribuição, também pouco considerada pelos estudos na área, é que trataremos conjuntamente os diversos aspectos que podem influenciar as escolhas dos ministros: políticos, técnicos e de proximidade com o presidente. Ao selecionar seus auxiliares, os presidentes fazem um cálculo complexo, envolvendo não só o relacionamento com o Legislativo, mas também as forças políticas regionais, os grupos organizados da sociedade, o contentamento dos eleitores, a implementação de políticas públicas, as caraterísticas pessoais dos ministros e suas próprias intuições e convicções, dando um caráter pessoalizado à gestão. É, portanto, fundamental controlar o efeito de outras variáveis que podem influenciar a formação do gabinete. O depoimento do ex-presidente Fernando Henrique Cardoso (FHC) sobre a escolha de um de seus ministros nos mostra como esses elementos são considerados:

Faltava resolver a questão do Ministério da Ciência e Tecnologia. Pareceu-me que seria forçar a barra nomear um deputado sem ligação com a área, [...] aí lembrei que, em Minas, o Israel Vargas poderia permanecer. Essa solução agradou a todos com quem conversei no estado e a quem consultei mais tarde: o presidente Itamar Franco e o Francelino Pereira, que estava muito aflito porque o PFL me havia apoiado e eles não tinham nada lá em Minas. Também conversou comigo o Jorge Bornhausen [então presidente do PFL]. Eles queriam outro nome. Eu disse: 'Olha, eu gosto muito do Ivan Botelho, mas não posso colocá-lo para a comunidade científica sem mais nem menos'. Entenderam. No dia seguinte, apareceu nos jornais que o Vargas seria pela via do PFL. Não é bem assim, mas ele tinha realmente um relacionamento bom com Francelino, e isso acalmou muitas áreas de Minas. Na véspera do anúncio, telefonei para o Vargas e disse: 'Olha, Zé' - ele é meu amigo de tantos anos - vou precisar de você, não sei bem onde”. E ele só soube pelo rádio que ia ser ministro da Ciência e Tecnologia. A questão mineira foi resolvida dessa maneira (Cardoso, 2015). 
Por fim, outra contribuição que nosso trabalho traz é o fato de termos ampliado o período de observação. Nossos dados abrangem todo o período da Nova República, totalizando aproximadamente 37 anos. Na seção que se segue, recuperamos a discussão acadêmica a respeito do tema.

\section{OS DIVERSOS FATORES CONSIDERADOS NO CÁLCULO DO PRESIDENTE}

Segundo Camerlo e Pérez-Liñan (2015), para exercer bem o mandato, os presidentes precisam de auxiliares que ofereçam três atributos principais: suporte político, habilidade técnica e lealdade. $\mathrm{O}$ primeiro seria fornecido sobretudo por aqueles que têm experiências política e partidária. O segundo, pelos tecnocratas, que são menos vulneráveis às pressões dos partidos políticos e dos eleitores. $\mathrm{O}$ terceiro, pelos seus aliados mais próximos, do mesmo partido e/ou amigos pessoais.

No Brasil, a discussão se concentrou no suporte político, basicamente envolvendo a distribuição dos ministérios aos partidos, a formação da coalizão e o consequente apoio dos partidos aos interesses do governo no Congresso Nacional. Apesar de os autores concordarem sobre a dominância do Executivo sobre o Legislativo, em geral as pesquisas focam sobre o último, e não no presidente ou na presidência da República. Pouco se sabe sobre a dinâmica interna desse poder (Batista, 2013; Rennó, 2016). Adotamos aqui uma estratégia diferente, olhando para a escolha dos ministros sob a óptica do presidente e controlando as características individuais dos ministros e sua aproximação com o chefe.

No que diz respeito ao contexto político, Abranches (1988), num dos artigos mais impactantes da ciência política brasileira, já nos alertava que a escolha dos ministros no Brasil envolvia dois eixos: o partidário e o estadual/regional. Em sua autobiografia, o ex-presidente Fernando Henrique Cardoso nos apresenta diversas evidências de como as duas lógicas funcionam na prática. Citamos abaixo uma delas:

\footnotetext{
Os dois peemedebistas escolhidos eram do Sul, dando margem a demandas regionalistas: como fica o Nordeste, onde o PMDB e o PFL têm tanta presença? E lá vinha o argumento das desigualdades regionais para dar sustentação a mais uma pretensão ministerial. Nas conversas com o PFL, eu escolhera um pernambucano para o Ministério e agora, para contentar o PMDB, a proposta era incluir um paraibano. Mas aí, como ficaria a Bahia, que pretendia o Ministério dos Transportes, se este fosse atribuído ao PMDB do Rio Grande do Sul? O embrulho era grande (Cardoso, 2006).
}

Tratamos a questão partidária apenas de forma lateral. Nosso foco principal será a influência regional. Na visão de D’Araújo e Ribeiro (2018), “o ministério é um dos principais recursos usados para a busca do precário equilíbrio federativo. Permite a busca sistemática de compensações alternativas para amenizar as desigualdades abissais entre as regiões”. A discussão é antiga e foi realizada com diferentes abordagens. Com frequência, salientou-se a preponderância dos estados e das regiões ricas, especialmente do Sudeste e de São Paulo. Alguns autores sugeriram a existência de uma barganha envolvendo cargos no Legislativo e no Executivo.

Soares (1973) observou que a limitação do número de deputados de São Paulo pela emenda constitucional de 1969 "não provocou qualquer reação, por que as forças políticas do estado perceberam que era melhor abandonar o problema da representação no Legislativo e focalizar na representação nos órgãos e postos importantes da administração pública, como os ministérios da Fazenda e do Planejamento". 
Ao avaliar empiricamente a situação, Abranches (1988) constatou que os ministérios política e economicamente estratégicos - na opinião dele, o da Fazenda e o da Agricultura - eram ocupados com base numa combinação partidária e regional. No primeiro, predominou São Paulo (41\%) no segundo, Pernambuco (59\%). O autor sugeriu ainda que os ministérios de "gastos" (ou de "clientelas") eram ocupados pelo critério essencialmente regional: os da Educação e da Saúde eram cativos da Bahia; o de Educação e Cultura teve predominância de São Paulo, Rio de Janeiro e Paraná; o de Viação e Obras Públicas teve $43 \%$ de seus titulares oriundos do Rio de Janeiro. No entanto, ao olharem para um período mais amplo (1889 a 2019), Neiva e Hiroi (2020) verificaram que tais suposições não se sustentavam. Souza (2006) chegou a dizer que "a política regional, em momentos críticos da política brasileira, tem suplantado os partidos como foco de aglutinação de forças políticas". Segundo ela, a barganha federativa passava pela sobrerrepresentação dos estados menos desenvolvidos no Congresso e pela predominância dos estados mais industrializados, em especial São Paulo, nas arenas decisórias relacionadas com as grandes políticas econômicas. Na opinião da autora, essa teria sido uma concessão das elites dos estados maiores aos seus aliados nos estados menores, a fim de combaterem o inimigo em comum: os setores emergentes dos grandes centros urbanos e industrializados. Em contrapartida, tais elites teriam uma participação nos vários nichos burocrático-administrativos ao largo dos partidos e do Congresso. Em outras palavras, parecia não haver dúvidas de que a representação dos interesses econômicos de São Paulo se exercia mediante outros canais representativos, pela articulação direta com os organismos burocrático-estatais. Essa seria a explicação para o pequeno investimento da elite paulista no fortalecimento dos partidos.

As sugestões de Soares (1973), Abranches (1988) e Souza (2006) dizem respeito à República Nova e ao período militar. Ames (1986) as mantém para a Nova República, ao afirmar que São Paulo permitiu que outros estados se apropriassem de pequenos projetos fisiológicos, enquanto permanecia controlando integralmente a política macroeconômica, os investimentos e as políticas fiscal e cambial. De acordo com o autor, os paulistas não estiveram nem sobre nem sub-representados nas pastas ministeriais, mas dominaram os órgãos cruciais: os ministérios da Fazenda e de Obras Públicas, além do Banco do Brasil.

Estudos posteriores confirmaram parcialmente tais hipóteses, ao verificar a predominância das regiões ricas nos gabinetes ministeriais. Meneguello (1998) identificou uma influência grande da região Sudeste, que chegou a obter 67\% dos cargos no governo FHC. Amorim (2004) percebeu que os três estados importantes da região (São Paulo, Rio de Janeiro e Minas Gerais) administraram metade do primeiro ministério do presidente Lula em 2003. A exemplo de outros autores, ele sugere que tal preponderância seria uma forma de compensar os estados grandes pela sub-representação parlamentar.

Em estudo posterior, porém, ao analisarem um período mais amplo, Amorim e Santos (2013) verificaram que a frequência de políticos cariocas no Executivo caiu de 15,7\% (no período democrático de 1946 a 1964) para 5,3\% (durante o regime militar) e, depois, para 4,6\% no período de 1985 a 2010. Identificaram também a queda de São Paulo e a ascensão de Minas Gerais e do Rio Grande do Sul durante o regime militar.

Neiva e Hiroi (2020) reforçaram alguns desses achados, ao identificar que as regiões Sul e Sudeste responderam por $68 \%$ dos ministros no período republicano. No caso do poderoso Ministério da Fazenda, o número chegou a $73 \%$, ou a $83 \%$, se forem considerados apenas os períodos democráticos. No também importante Ministério do Planejamento, a ocupação do cargo por políticos oriundos do 
Sudeste aconteceu em nada menos do que $88 \%$ das vezes. Já o percentual destinado ao Nordeste foi de apenas $6 \%$, ao passo que Norte e Centro-Oeste nunca chegaram a ocupar tal pasta. No que diz respeito aos ministérios militares, $78 \%$ ficaram nas mãos do Sul e do Sudeste, com destaque para os estados do Rio Grande do Sul (20,4\%) e do Rio de Janeiro (44,6\%).

Os fatores regionais também não são suficientes para explicar integralmente as escolhas dos presidentes. A situação ideal seria que cada ministro reunisse capacidade técnica e de articulação política, além de apresentar lealdade e confiança pessoal. Segundo Loureiro e Abrucio (1999), "cada vez mais os políticos vem baseando a sua atuação no discurso técnico e os burocratas reforçando o aspecto político no seu cálculo de atuação." No entanto, como nem sempre isso é possível, o presidente deve procurar manter esse equilíbrio de forma coletiva. No fim, sua equipe terá políticos, técnicos, técnicos-políticos, amigos pessoais e representantes de diversos segmentos.

Não foi possível neste trabalho incluir variáveis referentes aos partidos dos ministros ou às suas participações na coalizão de governo. Elas são importantes, mas nosso estudo valoriza outros aspectos que também podem influenciar a escolha do presidente, até porque a quantidade de ministros partidários nos sistemas presidencialistas tende a ser menor (Amorim \& Samuels, 2010; MartínezGallardo \& Schleiter, 2015). De fato, calculamos que um terço dos ministros não tinha filiação partidária no momento da nomeação. Se considerarmos que, entre os filiados, há também aqueles que não são necessariamente indicados pelos partidos (Camerlo \& Pérez-Liñan, 2015), a proporção de escolhidos à revelia desses últimos pode se aproximar de $40 \%$ ou mais. Não obstante, incluímos algumas variáveis de cunho político: se o ministro concorreu a alguma eleição antes da nomeação, se exerceu cargos de liderança no Legislativo e se foi parlamentar ou governador.

As análises centradas apenas em referências políticas não são, tampouco, suficientes para dar conta da complexa nomeação dos ministros. Ao criticarem as análises baseadas essencialmente nos partidos, Camerlo e Martinez-Gallardo (2017) alertam que o presidente precisa também do apoio de grupos extraparlamentares, de elites tecnocráticas e da opinião pública. Camerlo e Pérez-Liñan (2015) afirmam que, para assegurar a governabilidade, os presidentes dependem do suporte de grupos organizados, como sindicatos de trabalhadores, igrejas e militares, que podem ser cruciais em determinados momentos históricos. Na mesma linha, Inácio (2013) lembra que, apesar de os partidos interferirem diretamente na seleção dos ministros, eles o fazem sob constrangimentos impostos pelo presidente.

Camerlo e Pérez-Liñan (2015) ressaltam também que os dados sobre filiação partidária são fluidos, nem sempre confiáveis, difíceis de determinar e não refletem necessariamente as alianças políticas entre o Executivo e o Legislativo. Com frequência, os ministros partidários são apenas simpatizantes, sem peso político no partido. Portanto, não são necessariamente indicados por estes.

É preciso considerar ainda que os ministros podem ter interesses próprios que diferem dos do presidente. Os primeiros, como representantes do partido, têm ideologia, preferências políticas, projetos eleitorais e agenda próprios (Batista, 2018, 2013). Assim, os riscos e os custos de fiscalização e de controle do principal (o presidente) sobre seus agentes (os ministros) aumentam à medida que cresce o distanciamento de preferências entre eles. Desse modo, a nomeação de ministros sem filiação partidária pode contribuir para diminuir os riscos de agenciamento (Codato \& Franz, 2018; Martínez-Gallardo \& Schleiter, 2015; Palotti \& Cavalcante, 2019). Acrescente-se a isso o fato de terem aumentado a complexidade do aparato governamental, a heterogeneidade entre os ministérios e a presença de ministros não partidários e de tecnocratas, bem como ter declinado a legitimidade dos partidos (Camerlo \& Pérez-Liñan, 2015; Inácio, 2013), o que abriu espaço para novos enfoques. Na 
América Latina como um todo, os especialistas vêm se interessando pelos temas da formação, da estabilidade e da duração do gabinete (Rennó, 2016).

Essas mudanças trouxeram também um interesse renovado por outras características dos ministros: pessoais/individuais, como gênero, nível educacional, profissão, competência técnica; representatividade das forças políticas e sociais que ajudaram a eleger o presidente, as quais não estão necessariamente atreladas aos partidos, como grupos étnicos, religiosos, profissionais, estudantis, empresariais, movimentos sociais, entre outros; outsiders, próximos e leais aos presidentes (Carmelo \& Pérez-Liñan, 2015).

Na mesma linha, Palotti e Cavalcante (2019) consideram que a nomeação de ministros pode ampliar o caráter representativo do governo sob diferentes perspectivas, envolvendo as forças políticas e sociais que deram apoio ao governo e não estão necessariamente atreladas às alianças do Congresso Nacional e à implementação de políticas públicas. Segundo os autores, aspectos regionais, étnicos e religiosos, grupos de pressão e de interesse, movimentos sociais, atributos pessoais/profissionais e da burocracia estatal também importam nessa complexa equação.

A literatura a respeito do tema no Brasil não é tão grande, mas existe. Codato e Franz (2018) verificaram que tanto os ministros "políticos" quanto os "não políticos" tinham larga experiência, inclusive administrativa. Os autores constataram pouca diferença entre os governos do PSDB e do PT, contrariando parcialmente a visão recorrente de que o governo FHC promoveu gabinetes mais gerenciais, enquanto Lula teria politizado o Executivo (Inácio, 2013).

Palotti e Cavalcante (2018) procuraram identificar o impacto de variáveis relacionadas com a filiação política, a formação educacional e a experiência profissional. Os autores observaram que, em geral, os ministros eram experientes e com boa formação profissional. Loureiro, Abrucio e Rosa (1998) avaliaram a seleção dos ministros nos governos José Sarney, Fernando Collor de Mello, Itamar Franco e FHC com base em cinco critérios: partidário, qualificação técnica, indicação de grupos de interesse, imagem perante a opinião pública e federativo. Na seção que se segue, apresentamos nossos dados, que abrangem diversas variáveis discutidas até aqui.

\section{APRESENTAÇÃO E INTERPRETAÇÃO DOS DADOS}

Estamos trabalhando com quase todos os ministros nomeados na Nova República, desde 1985 até 2021, baseados em dados extraídos do Centro de Pesquisa e Documentação de História Contemporânea (CPDOC) da Fundação Getulio Vargas (FGV), de acervos de jornais, dos sites oficiais da Câmara dos Deputados e do Senado, entre outros. Como nossa unidade de análise é a nomeação para o ministério, os dados se referem ao que aconteceu antes dela. Não interessa, portanto, os cargos que o ministro ocupou após o mandato.

Além dos ministérios efetivos, consideramos também aqueles que tinham status de ministério, com exceção do Banco Central (BC) e da Advocacia-Geral da União (AGU), por envolveram escolhas essencialmente técnicas. Não foram considerados os ministros que exerceram o cargo de modo interino nem militares, a não ser os nomeados para o Ministério da Defesa.

Nesse período, o Brasil foi governado por oito presidentes, que exerceram onze mandatos. No total, o país contou com 94 ministérios diferentes, que podem ser reduzidos a 39, quando desconsideramos as meras mudanças de nomes ou os agregamos por área de atuação. Nossa unidade de análise são as nomeações, que chegaram a 578 no período de quase 37 anos, independentemente do tempo de 
duração do exercício do cargo. Isto é, contamos como nova observação (nomeação) toda vez que há posse de um ministro, inclusive no caso em que ele é mantido quando há mudança de mandato presidencial.

O número total de indivíduos é menor (419), já que conta como nova observação a nomeação do ministro para outro ministério ou para o mesmo, mas em outro momento. De igual modo, contamos como nova nomeação a manutenção de um ministro quando o presidente é reeleito, conforme fizeram outros pesquisadores (Codato \& Franz, 2018; Palotti \& Cavalcante, 2018). A ex-presidenta Dilma Rousseff, por exemplo, aparece no banco de dados três vezes: como ministra de Minas e Energia e como chefe da Casa Civil duas vezes, no primeiro e no segundo mandatos de Luiz Inácio Lula da Silva.

Nossa variável dependente reflete a saliência/relevância dos ministérios, conforme indicador proposto por Zucco, Batista e Power (2017). A medida se baseia nas respostas de 142 parlamentares a um questionário, no qual opinaram sobre a atratividade de cada um dos ministérios para os políticos. Os autores usaram o conhecido modelo de probabilidade Bradley-Terry, o qual permite que as escolhas sejam feitas par a par, evitando a difícil classificação ordinal de um número tão grande de opções. O índice varia de 0 a $-4,21$. Quanto menor o número (isto é, quanto mais negativo), menor é a atratividade do ministério. $\mathrm{O}$ valor 0 , portanto, reflete o ministério mais valorizado pelos políticos.

Os autores aplicaram o mesmo questionário para um grupo de 283 especialistas, filiados à Associação Brasileira de Ciência Política $(\mathrm{ABCP})$. Os dois índices apresentaram alta correlação entre si, com coeficiente linear de 0,87 . Optamos pelo primeiro por considerar que os políticos, em especial os parlamentares, têm uma visão mais apurada do contexto que os cerca no seu dia a dia. Essa é também a avaliação de Mauerber e Pereira (2020), que afirmam que a "a visão dos legisladores reflete realmente o que interessa quando se fala em ministérios, dado que eles são os responsáveis por indicar seus aliados para ocupar tais posições".

Utilizamos como base os 37 ministérios entre 2014 e 2015, os últimos dois anos da administração de Dilma. Como os ministérios não são exatamente os mesmos ao longo de todo o período, classificamos por aproximação os que faltaram. ${ }^{1}$ Essa estratégia não é perfeita, já que, além das diferenças de estrutura e de atribuições, os governos priorizam as pastas de forma diferente. Ainda assim, acreditamos que tais distorções não inviabilizem nosso trabalho. Temos dois pontos a favor da nossa escolha: primeiro, o fato de o segundo governo Dilma ter sido o que contou com maior número de ministérios, reduzindo o problema da adaptação do indicador para outros governos. Em segundo lugar, há que considerar que os pesos das pastas não são tão diferentes assim - os ministérios da Fazenda, do Planejamento e a Casa Civil, por exemplo, são fortes em qualquer governo, contrastando com os da Cultura ou do Meio Ambiente, que foram menos valorizados por todos os presidentes.

Nossas variáveis explicativas principais dizem respeito aos fatores regionais. Elas serão testadas de três formas diferentes: por meio da região (o Sudeste, em comparação com as outras), do estado (São Paulo, em comparação com os outros) e utilizando um índice que reflete a desproporcionalidade de representação de cada estado no Senado (a casa federativa e mais desproporcional). Nos dois primeiros casos (Sudeste e São Paulo), o sinal esperado é positivo. No último, negativo, já que os

\footnotetext{
${ }^{1}$ Por não acharmos um equivalente adequado, deixamos de fora os ministérios da Desburocratização e Extraordinário para Assuntos de Irrigação.
} 
estados economicamente desenvolvidos tendem a ser subrepresentados no Legislativo. Até certo ponto, a desproporcionalidade testa a hipótese levantada por alguns autores (Amorim, 2004; Soares, 1973; Souza, 2006) de que os estados ricos cederam a sobrerrepresentação dos pobres no Legislativo em troca da preponderância no governo federal, especialmente nos ministérios mais expressivos.

A literatura tem sinalizado que há uma preponderância de ministros do Sudeste, principalmente de São Paulo (D’Araújo \& Ribeiro, 2018; Palotti, 2017). D’Araújo e Ribeiro (2018) verificaram também que a região teve uma participação maior nos ministérios ligados à economia, às finanças, à gestão e ao planejamento, chegando a ser responsável por $85 \%$ dos cargos. Nossos dados reforçam parcialmente esses achados: mais da metade dos ministros são oriundos daquela região. Eles mostram também que a área prevalece em alguns ministérios relevantes, como Fazenda (82\%), Planejamento (67\%), Casa Civil (59\%) e Saúde (62\%).

As variáveis de controle se baseiam nos perfis dos respectivos ministros, envolvendo quatro aspectos principais: características pessoais, políticas, técnicas e de lealdade ao presidente. No primeiro aspecto, os valores que encontramos são próximos aos identificados por outros autores (Codato \& Franz, 2018; D’Araujo \& Ribeiro, 2018; Palotti \& Cavalcante, 2019). Os ministros da Nova República têm, em média, idade de 55 anos, $92 \%$ são homens, 93,4\% têm formação superior, $24,2 \%$ contam com mestrado e $20,6 \%$, com doutorado.

Encontramos 58 profissões diferentes, que foram agregadas em 14, para facilitar a análise. Embora seja comum os ministros terem mais de uma profissão/ocupação, consideramos apenas a principal, muitas vezes conectada à área de formação. Ainda que não seja uma característica decisiva para a escolha, os presidentes parecem levá-la em consideração, conforme mostram os números: os economistas predominaram nos Ministérios da Fazenda (36\%) e do Planejamento (48\%), ao passo que os professores tiveram participação importante no Ministério da Educação (57\%). No da Justiça, encontramos metade de advogados; no das Relações Exteriores, 53\% eram diplomatas; na Saúde, $62 \%$ eram médicos. Para evitar excesso de informação, trabalharemos apenas com as profissões mais importantes no nosso modelo de regressão.

Classificamos os ministros como "políticos" ou "não políticos" com base no fato de já terem participado de uma eleição ou terem sido filiados a partidos, que são duas formas claras de demonstrar interesse pela política. Aproximadamente $67 \%$ deles se enquadraram nessa situação, número próximo aos 66\% encontrados por Palotti e Cavalcante (2018). Isso mostra que, a despeito da importância dos partidos, o presidente tem uma margem de manobra, já que escolhe uma parte razoável do gabinete sem a referência partidária. Ela é maior se considerarmos que nem todos os ministros vinculados a partidos são de fato indicação destes. No apêndice, mostramos o percentual de ministros políticos em cada um dos ministérios mais importantes.

No que diz respeito aos principais cargos eletivos exercidos antes de assumirem o ministério (deputado federal, senador e governador), 53\% dos ministros passaram por pelo menos um deles, número levemente superior aos 45\% encontrados por Palotti e Cavalcante (2018): 38\% foram deputados federais; $14 \%$, senadores; e $10 \%$, governadores.

Segundo Inácio (2013), a ocupação de cargos de direção e de liderança partidárias é um aspecto relevante para ser escolhido para um ministério. De acordo com a autora, os partidos tendem a privilegiar a elite interna, os políticos profissionais, que costumam ter fortes vínculos com a organização. De fato, 122 dos 578 ministros da nossa amostra (21\%) passaram por pelo menos um 
desses cargos. Resta saber se tais pastas são as mais valorizadas politicamente. Entram nessa variável as seguintes categorias: presidentes da Câmara dos Deputados e do Senado, líderes do governo e de partido político no Congresso Nacional, presidentes e secretários-gerais de partidos, fundador de partido de médio ou grande porte e presidente de bancada suprapartidária.

Ainda na "dimensão" política, consideramos o exercício de líderes sociais de dois tipos. Um deles reflete a direção de grupos organizados da sociedade em diversas áreas (estudantil, profissional, artístico, esportivo, religioso, segmentos minoritários) - 13\% dos ministros se enquadram nessa classificação. O outro tipo se refere aos grupos empresariais - 45 ministros. A categoria abrange aqueles que sobressaíram no meio, seja por terem participado da direção de associações - como Federação das Indústrias do Estado de São Paulo (Fiesp), Confederação Nacional da Indústria (CNI) ou Federação Brasileira de Bancos (Febraban) -, seja por terem dirigido grandes empresas. Sua participação na maioria dos ministérios é nula ou baixa. As exceções ficam por conta dos Ministérios da Agricultura (29\%), da Fazenda (32\%) e de Indústria e Comércio (40\%).

Trabalhamos também com variáveis de natureza "técnica" ou "tecnocrática", que envolvem o exercício de cargos de natureza não estritamente política. Conforme dito pela literatura, em geral, os ministros têm alta qualificação técnica, quase todos têm formação superior e 30\% fizeram mestrado e/ou doutorado. A competência técnica passa também pela experiência administrativa. Codato e Franz (2018) verificaram que grande parte dos ministros a tinha quando assumiu o mandato. Eles verificaram pouca diferença em função da natureza dos ministérios (política, social, econômica), com exceção dos ministérios sociais nos governos do PT, em que os ministros tinham menos experiência administrativa.

Ao contrário de Codato e Franz (2018), consideramos os secretários de ministério como sendo de natureza mais técnica do que política. Aqui entram tanto os que ocuparam secretarias específicas quanto os secretários executivos - uma espécie de vice-ministro. Muitas vezes, trata-se de alguém que conhece bem a pasta e serve como alternativa nas situações em que o presidente pretende dar um caráter mais técnico ao ministério, em "mandatos tampões" ou no fim de governo. Pereira, Praça, Batista e Lopes (2015) sugerem que eles são utilizados para monitorar os ministros, sobretudo quando são de um partido distante das preferências do presidente. Encontramos 147 ex-secretários, equivalentes a um quarto da nossa amostra.

Alguns ministros são escolhidos por vontade própria do presidente, dentro da chamada "cota pessoal", que envolve diversas situações. Uma delas diz respeito às pessoas que gozam da confiança do presidente, como amigos, assessores e auxiliares próximos, geralmente que os acompanharam em suas carreiras políticas. Essas relações independem das conexões político-partidárias, embora algumas delas possam vir do próprio partido do presidente. Identificamos 70 ministros nessa situação, ou $12 \%$ de todos eles. Entram também na "cota pessoal" os ministros que participaram da campanha eleitoral para a presidência, como coordenadores, tesoureiros ou assessores especiais em determinada área. Na nossa amostra, 86 ministros (15\%) estão nessa situação.

Podemos ainda incluir na cota pessoal do presidente as celebridades. Trata-se de outsiders, sem experiência política, que aparentemente cumprem a função de trazer maior popularidade ao governo. Identificamos apenas 12 ministros nessa situação. Estão no grupo os jogadores de futebol Pelé e Zico, o jogador de vôlei Bernard, a atriz Regina Duarte, o cantor Gilberto Gil, entre outros. 


\section{ANÁLISE MULTIVARIADA}

As variáveis apresentadas na seção anterior não são suficientes, individualmente, para explicar os fatores considerados pelo presidente ao fazer suas escolhas. Uma análise mais adequada deve considerá-las conjuntamente, de forma que possamos avaliar a influência efetiva de cada uma delas, controlando a de todas as outras.

$\mathrm{Na}$ tabela que se segue, apresentamos três modelos de regressão linear diferentes. Dessa forma, podemos avaliar separadamente o comportamento das variáveis que dizem respeito aos fatores regionais: o fato de ser oriundo do Sudeste ou de São Paulo e a desproporcionalidade de representação no Senado, a casa federativa. Eles permitem também testar variáveis supostamente próximas em modelos separados, como ser empresário e ter conexão empresarial. Com os três modelos, podemos ter maior segurança nas nossas conclusões, já que nos possibilita avaliar sua estabilidade em diferentes contextos.

TABELA 1 DETERMINANTES DA ESCOLHA DOS MINISTROS, DE ACORDO COM A RELEVÂNCIA DOS MINISTÉRIOS

\begin{tabular}{|c|c|c|c|}
\hline Variáveis independentes & Modelo 1 & Modelo 2 & Modelo 3 \\
\hline Sudeste & $\begin{array}{c}0,11 \\
(0,87)\end{array}$ & - & - \\
\hline Desproporcionalidade do estado no Senado & - & $\begin{array}{c}-0,00 \\
(-0,12)\end{array}$ & - \\
\hline São Paulo & - & - & $\begin{array}{l}0,28^{\star \star} \\
(2,08)\end{array}$ \\
\hline Idade (anos) & $\begin{array}{l}-0,00 \\
(-0,63)\end{array}$ & - & - \\
\hline Mulher & $\begin{array}{c}-0,82^{\star \star \star} \\
(-3,90)\end{array}$ & $\begin{array}{c}-0,83^{\star \star \star} \\
(-4,09)\end{array}$ & $\begin{array}{c}-0,80^{\star \star \star} \\
(-3,96)\end{array}$ \\
\hline Advogado & $\begin{array}{c}-0,08 \\
(-0,52)\end{array}$ & - & - \\
\hline Economista & $\begin{array}{c}0,98^{\star \star \star} \\
(4,86)\end{array}$ & $\begin{array}{c}0,98^{\star \star \star} \\
(5,04)\end{array}$ & $\begin{array}{c}1,02^{\star \star \star} \\
(5,23)\end{array}$ \\
\hline Empresário & $\begin{array}{c}0,29 \\
(1,53)\end{array}$ & - & $\begin{array}{c}0,27 \\
(1,55)\end{array}$ \\
\hline Conexão empresarial & - & $\begin{array}{c}0,46^{\star \star \star} \\
(2,29)\end{array}$ & - \\
\hline Doutorado & $\begin{array}{l}0,31^{\star *} \\
(2,05)\end{array}$ & $\begin{array}{l}0,33^{\star *} \\
(2,33)\end{array}$ & $\begin{array}{l}0,29^{\star \star} \\
(2,01)\end{array}$ \\
\hline Político & $\begin{array}{l}-0,03 \\
(-0,16)\end{array}$ & - & - \\
\hline
\end{tabular}


RAP | A relação entre demanda e desempenho dos magistrados: investigação de um modelo funcional em forma de U invertido

\begin{tabular}{|c|c|c|c|}
\hline Variáveis independentes & Modelo 1 & Modelo 2 & Modelo 3 \\
\hline Deputado federal & $\begin{array}{c}0,05 \\
(0,34)\end{array}$ & - & - \\
\hline Senador & $\begin{array}{c}0,35 \\
(0,86)\end{array}$ & - & - \\
\hline Governador & $\begin{array}{c}0,25 \\
(1,23)\end{array}$ & $\begin{array}{c}0,29 \\
(1,51)\end{array}$ & $\begin{array}{c}0,26 \\
(1,39)\end{array}$ \\
\hline Liderança política & $\begin{array}{c}0,24 \\
(1,57)\end{array}$ & $\begin{array}{l}0,25^{\star \star} \\
(1,87)\end{array}$ & $\begin{array}{l}0,23^{*} \\
(1,68)\end{array}$ \\
\hline Secretário de Ministério & $\begin{array}{l}0,09 \\
(0,66)\end{array}$ & - & - \\
\hline Cargo técnico nacional & $\begin{array}{c}0,17 \\
(1,18)\end{array}$ & - & - \\
\hline Liderança social & $\begin{array}{c}-0,48^{\star \star \star} \\
(-2,72)\end{array}$ & $\begin{array}{c}-0,53^{\star \star \star} \\
(-3,18)\end{array}$ & $\begin{array}{c}-0,55^{\star \star \star} \\
(-3,23)\end{array}$ \\
\hline Celebridade & $\begin{array}{c}-1,23^{\star \star \star} \\
(-3,14)\end{array}$ & $\begin{array}{c}-1,24^{\star \star \star} \\
(-3,27)\end{array}$ & $\begin{array}{c}-1,25^{\star \star \star} \\
(-3,31)\end{array}$ \\
\hline Proximidade pessoal com o presidente & $\begin{array}{c}0,23 \\
(1,29)\end{array}$ & $\begin{array}{c}0,18 \\
(1,04)\end{array}$ & - \\
\hline Participação na campanha eleitoral & $\begin{array}{c}0,04 \\
(0,27)\end{array}$ & - & - \\
\hline Constante & $\begin{array}{l}-2,52 \\
(-6,62)\end{array}$ & $\begin{array}{l}-2,79 \\
(0,12)\end{array}$ & - \\
\hline Observações & 576 & 578 & 578 \\
\hline R-squared & 0,18 & 0,18 & 0,18 \\
\hline
\end{tabular}

${ }^{* * *} \mathrm{p}<0.01,{ }^{* *} \mathrm{p}<0.05,{ }^{*} \mathrm{p}<0.1 \quad$ teste "t" entre parênteses.

Obs.: Embora não tenham sido mostradas nesta tabela, as regressões foram estimadas com variáveis dummies que controlam os efeitos fixos referentes a todos os governos.

Fonte: Elaborada pelos autores.

Iniciamos a análise pela nossa hipótese principal, que envolve a questão regional. As variáveis referentes a ela apresentaram comportamentos diferentes. A literatura mostrou que o fato de ser oriundo do Sudeste aumenta a probabilidade de ocupar um ministério (Amorim, 2004; D’Araújo \& Ribeiro, 2018; Meneguello, 1998; Neiva \& Hiroi, 2020). Porém, nossos dados mostram que isso não está relacionado com o peso político desse ministério. O teste "t" de 0,87 da variável "Sudeste" (modelo1) revela que a região está longe de apresentar significância estatística.

De fato, é expressiva a presença de ministros do Sudeste em ministérios importantes, mas eles têm presença forte também nos ministérios menos cobiçados pelos políticos, como Esportes (87\%), Direitos das Mulheres (83\%) e Igualdade Racial (83\%). Esses dados sugerem que o Sudeste lidera não apenas uma agenda econômica, mas também uma "pós-materialista", que prioriza valores individuais de autonomia e autoexpressão, em detrimento de valores materialistas, físicos e econômicos (Inglehart, 2015). 
De todo modo, os resultados referentes à região não são taxativos. É preciso lembrar que, conquanto facilite a análise, a agregação de estados muito diferentes numa mesma região pode gerar distorções. No caso do Sudeste, por exemplo, abrange tanto o estado de São Paulo, o mais populoso e o centro econômico do país, quanto o Espírito Santo, um estado bem menor, com menos de 2\% da população.

A variável que identifica a desproporcionalidade de representação dos estados no Senado também não apresentou significância estatística (modelo 2). Fica enfraquecida a hipótese colocada por diversos autores de que os estados mais ricos trocaram a subrepresentação no Legislativo pela preponderância nos cargos mais importantes no Executivo. Isso se confirma no que concerne ao número de ministérios ocupados, mas não no que se refere ao peso deles.

É importante notar, no entanto, que a desproporcionalidade de representação no Legislativo está muito concentrada na subrepresentação de São Paulo, inclusive na Câmara dos Deputados - a casa que, em princípio, deveria ser proporcional à população. Isso se dá em função da emenda constitucional que limita o número de cadeiras naquela casa a 70, afetando particularmente aquele estado. Assim, não podemos descartar totalmente a hipótese da barganha entre estados grandes e pequenos. Talvez sua medida distribuída por todos os estados não represente exatamente o pacto que pode ter sido feito entre São Paulo e os estados menores, e não entre todos os estados da federação. Até por isso, é importante reservar uma variável que identifique aquele estado em particular.

A mesma tese é aplicada no modelo 3, que apresentou significância estatística ao nível de 5\%, sugerindo que o estado predomina não apenas no número de ministérios ocupados, conforme identificado por vários autores (D’Araújo \& Ribeiro, 2018; Figueiredo, 2007; Palotti, 2017), mas também no peso relativos que eles têm. Fizemos a mesma análise nos modelos 1 e 2 , substituindo as variáveis "sudeste" e "desproporcionalidade no Senado" pela variável referente a São Paulo. Os resultados mostram que o fato de o ministro ser oriundo do estado está relacionado com a força do ministério.

Esses achados reforçam as hipóteses antigas (Abranches, 1988; Ames, 1986; Soares, 1973; Souza, 2006), nunca testadas efetivamente, que sugerem a prevalência de São Paulo no governo federal, tanto em termos numéricos quanto em relação às agências estatais que controla. $\mathrm{O}$ estado, de fato, ocupou alguns dos ministérios mais importantes na Nova República.

Obviamente, o fator regional tampouco explica sozinho a ocupação dos cargos ministeriais. Assim, é fundamental controlar outros fatores que supostamente influenciam nesse sentido. No que diz respeito às características pessoais, os resultados mostram que não há qualquer relação entre a idade do ministro e a importância do ministério que ocupa. Já o fato de ser mulher está negativamente relacionado. A variável apresentou alta significância estatística nos três modelos. Isso porque se destinou às mulheres ministérios mais ligados à área social e a políticas assistencialistas e voltadas às minorias, que são bem menos valorizados pelos parlamentares: Igualdade Racial (67\%), Desenvolvimento Social (36\%) e Direitos Humanos (35\%). Em ministérios importantes, como os da Fazenda e do Planejamento, elas exerceram o cargo apenas 4,6\% e 4,7\% das vezes, respectivamente. Isso mostra que perdura no Brasil a ideia de que a área de atuação da mulher é a da família, do cuidado, da reprodução e do assistencialismo, concepção que acaba se refletindo na atuação governamental. Mostra também como é equivocado avaliar a participação das mulheres na política apenas pelos números.

Com relação às profissões dos ministros, podemos observar que a mais frequente delas (advogado) se distribui de maneira mais ou menos equitativa, a despeito da força dos ministérios. A variável que lhe diz respeito, com teste " $\mathrm{t}$ " de -0,52, está longe de apresentar significância estatística. Já os ministros 
economistas tendem a ser alocados para ministérios mais importantes - a variável apresentou alta significância estatística em todos os três modelos.

Em geral, os empresários podem ter tido algum espaço nos ministérios mais relevantes. A variável referente àquela profissão esteve próxima de apresentar significância estatística, com "p" valores de 0,12 (não mostrados na tabela) nos dois modelos em que entrou. No entanto, trata-se de uma variável muito abrangente, que envolve todos os tipos de empresários. A importância do segmento aparece mais claramente na variável que indica se o ministro teve alguma conexão com as grandes empresas, seja ocupando cargos de direção, seja participando de organizações de classe. Nesse caso, apresentou alta significância estatística, ao nível de $1 \%$.

Os resultados mostram que os ministérios mais expressivos receberam uma quantidade maior de ministros com boa formação acadêmica, aqui medida pela conclusão de um curso de doutorado. A variável se apresentou significativa ao nível de $5 \%$ nos três modelos.

Ainda em relação à qualificação técnica, observamos que o fato de o ministro ter ocupado secretarias ministeriais não teve qualquer impacto sobre nossa variável dependente. Isso não quer dizer que a ocupação de cargos desse tipo não importe na conquista do ministério. Como vimos, a frequência de ex-secretários é grande - um quarto deles passou por tais cargos. Mas isso acontece tanto nos ministérios fortes quanto nos fracos. Avaliamos também a ocupação do que estamos chamando de "cargos técnicos nacionais", que não se mostrou significativa. Porém, a diversidade de cargos considerados talvez dificulte chegarmos a conclusões mais robustas; entram aí desde ministros de tribunais superiores até consultores legislativos, passando por presidentes e diretores de órgãos estatais, como bancos, Instituto Nacional do Seguro Social (INSS) etc.

Analisamos a dimensão política de várias formas. A primeira delas, por meio da variável "político", que informa se o ministro teve alguma vinculação política antes de ser empossado. A mesma não se apresentou significativa no modelo em que foi incluída. Outra forma que utilizamos para avaliar a questão política foi por meio dos cargos eletivos exercidos. $\mathrm{O}$ fato de terem sido deputado federal ou senador não apresentou significância estatística, isto é, não mostrou correlação expressiva com a importância do ministério que ocuparam. Uma possível explicação é que os parlamentares costumam se especializar em algumas políticas públicas, o que lhes credencia a ocupar certos ministérios. Embora possam ser eleitoralmente interessantes para tais ministros, eles não são necessariamente os mais cobiçados pela maioria. Isso talvez ajude a explicar os achados de Batista (2018) de que os parceiros da coalizão "não respondem de forma diferente em termos de apoio legislativo em função dos diferentes ativos que recebem na distribuição dos ministérios".

A variável "liderança política" apresentou um comportamento instável - nenhuma significância estatística no primeiro modelo, $5 \%$ no segundo e $10 \%$ no terceiro. Ao que parece, as elites partidárias tendem a ocupar os ministérios mais importantes. Vale lembrar que os líderes sempre têm papel de destaque. Se não forem eles próprios os ocupantes dos cargos, muitas vezes participam das indicações.

A variável "liderança social" se apresentou inequivocamente significativa nos três modelos (ao nível de 1\%). Devemos atentar no sinal negativo, mostrando que tal experiência favorece a escolha para ministérios menos prestigiados, em geral na área em que tais lideranças militam: minorias, direitos humanos, desigualdade social, meio ambiente. De acordo com Codato e Franz (2018), trata-se de atores que se tornam ministeriáveis sem uma carreira intensa, seja técnica, seja política.

As três variáveis finais estão mais vinculadas às decisões pessoais dos presidentes. No caso da que se refere às celebridades, ela apresentou sinal negativo e alta significância estatística nos três modelos 
em que entrou. Os resultados não surpreendem, dado que boa parte delas está concentrada nos ministérios dos esportes e da cultura. Trata-se de figuras conhecidas da população, como músicos, atletas e atores.

As variáveis "proximidade pessoal" e "participação na campanha" envolvem maior aproximação e lealdade ao presidente. Nenhuma das duas se mostrou significativa nos modelos em que entraram. Pessoas próximas ao presidente costumam participar do governo; porém, não necessariamente nos ministérios mais relevantes.

No período estudado, o país experimentou vários governos diferentes. Controlamos também o efeito de cada um deles inserindo variáveis "dummies", as quais não trazem informações relevantes. Deixamos de incluí-las na tabela para poupar o leitor de um excesso de informações.

Não obstante, cabe fazer um relato especial sobre o governo Jair Bolsonaro, que é o que mais se distanciou de todos os outros na forma de seleção dos ministros. Ele está há dois anos e meio no poder e responde por apenas 7\% dos ministros nomeados em toda a Nova República, o que dificulta conclusões mais robustas do ponto de vista estatístico. No entanto, conseguimos perceber algumas diferenças. Foi o governo que, proporcionalmente, alocou o maior número de empresários no gabinete: $24,4 \%$, contra uma média geral de $11,6 \%$. Foi o segundo presidente a contratar mais políticos do próprio estado de origem: 29,3\%, contra uma média de 19,4\%. Foi o segundo a selecionar menos ministros com doutorado: 9,8\%, contra $20,6 \%$ de média geral.

O governo Bolsonaro ficou conhecido também pelo espaço dados aos militares. No início do mandato, a revista Veja publicou uma reportagem dizendo que Bolsonaro era o segundo presidente a recrutar mais militares para o gabinete (Romano, 2019). Naquele momento, tinha oito ministros militares. Só ficava atrás de Castelo Branco, que nomeou doze militares para seu governo. Hoje, Bolsonaro já ultrapassou essa marca, se considerarmos o número absoluto de nomeações: nada menos que treze dos quarenta e um ministros que passaram pelo seu governo eram militares.

Chama a atenção também o pequeno número de paulistas no seu governo: apenas 7,3\%, contra $24,4 \%$ na média geral. É curioso que o presidente mais radical de toda a Nova República seja também o que tem menos ministros originários de São Paulo. Talvez seja mais uma forma de se contrapor aos partidos que predominaram no governo do país nas últimas décadas (PT e PSDB), os quais têm uma base forte em São Paulo. Difícil dizer com precisão qual seja a sua estratégia, mas parece que o fator regional também entra em seu cálculo político.

\section{CONSIDERAÇÕES FINAIS}

Neste artigo, buscamos avaliar os fatores considerados pelo presidente para escolher seus ministros. Diferentemente de grande parte dos estudos na área, não nos preocupamos apenas com o número de ministérios, mas sobretudo com seu peso político. Outro diferencial da pesquisa é que montamos um modelo multivariado, em que podemos enxergar mais apropriadamente o comportamento de cada variável no conjunto. Não é demais reforçar que as escolhas do presidente são feitas levando em conta diversos fatores, que não se excluem entre si. Eles estão presentes nas nomeações individuais e no resultado coletivo. No fim, o gabinete deve refletir um complexo de forças políticas predominantes na sociedade, as necessidades de sustentação política e de produzir políticas públicas eficientes, as perspectivas eleitorais, o estilo e a intuição do próprio presidente. 
No geral, percebemos que fatores relacionados com o ambiente econômico e a classe empresarial parecem contribuir para a ocupação dos ministérios mais importantes. Há também algumas indicações de que os ministérios menos relevantes têm conexões com a representação de minorias, seja pela maior presença das mulheres, seja pela presença de lideranças sociais.

Nossas questões principais estão ligadas à influência regional. Reforçamos parcialmente hipóteses antigas. Não foi possível confirmar qualquer relação entre a suposta barganha (ou compensação) entre as desproporcionalidades de representação no Legislativo e no Executivo. Ou seja, estados sub-representados no primeiro não ocupam os ministérios mais relevantes no segundo, ou vice-versa, contrariando hipóteses apresentadas pela literatura.

Os dados, todavia, sugerem que algo acontece no estado mais rico e mais subrepresentado. São Paulo ocupa proporcionalmente o maior número de cargos ministeriais e está presente também nos mais importantes. Tais cargos estão relacionados com alguma representação empresarial. Para complicar a situação, ministérios ligados a uma "agenda pós-materialista" - e não necessariamente prestigiados - recebem um contingente grande de titulares paulistas.

É preciso considerar que São Paulo foi o estado mais afetado pela subrepresentação em ambas as casas do Congresso, sobretudo em função da limitação do número de deputados. Talvez a barganha política tenha ocorrido não entre blocos regionais, e sim entre São Paulo e os estados pobres.

Vivenciamos hoje uma profunda disputa entre o governo Bolsonaro e os governadores em torno das políticas relacionadas com a pandemia, à revelia dos partidos. No entanto, a ciência política parece "meio perdida" no entendimento do fenômeno. Obviamente, não temos a pretensão de resolver isso agora; apenas chamamos a atenção para outros fatores relevantes sobre os quais devemos nos debruçar. O debate sobre as relações entre as forças políticas regionais e o governo central é um deles.

Acreditamos que as discussões em torno da presidência, bem como as relacionadas com o federalismo, precisam ser reabertas. Muita coisa ficou pendente aqui. Estudos futuros podem enveredar por outros caminhos. Cabe investigar o papel de outros estados nesse jogo. É muito curiosa, por exemplo, a predominância de militares oriundos do Rio Grande do Sul e do Rio de Janeiro, além do caso de Minas Gerais, que já foi chamada de "o fiel da balança da federação". 


\section{REFERÊNCIAS}

Abranches, S. (1988). Presidencialismo de coalizão: o dilema institucional brasileiro. Dados, 31(1), 5-38.

Amorim, O., Neto. (2000). Gabinetes presidenciais, ciclos eleitorais e disciplina legislativa no Brasil. Dados, 43(3), 479-519. Recuperado de https://doi. org/10.1590/S0011-52582000000300003

Amorim, O., Neto. (2004). O Poder Executivo, centro de gravidade do sistema político brasileiro. In L. Avelar, \& A. O. Cintra (Orgs.), Sistema político brasileiro: uma introdução. São Paulo, SP: Fundação Editora Unesp.

Amorim, O., Neto, \& Samuels, D. (2010). Democratic regimes and cabinet politics: a global perspective. Revista Ibero-Americana de Estudos Legislativos, 1(1), 10-23. Recuperado de https://doi.org/10.12660/ riel.v1.n1.2010.4123

Amorim, O., Neto, \& Santos, F. (2013). O Rio de Janeiro e o Estado Nacional (1946-2010). Dados, 56(3), 467-496. Recuperado de https://doi. org/10.1590/S0011-52582013000300001

Batista, M. (2013). O poder no Executivo: uma análise do papel da presidência e dos ministérios no presidencialismo de coalizão brasileiro (1995-2010). Opinião Pública, 19(2), 449-473. Recuperado de https://doi.org/10.1590/S0104-62762013000200009

Batista, M. (2018). Who gets what and how does it matter? Importance-weighted portfolio allocation and coalition support in Brazil. Journal of Politics in Latin America, 10(3), 99-134. Recuperado de https:// doi.org/10.1177/1866802X1801000304

Camerlo, M., \& Martinez-Gallardo, C. (2017). Government formation and minister turnover in presidential cabinets: comparative analysis in the Americas. Nova York, NY: Routledge.

Camerlo, M., \& Pérez-Liñan, A. (2015). The politics of minister Retention in presidential systems technocrats, partisans, and government approval. Comparative Politics, 47(3), 315-333. Recuperado de https://doi.org/10.5129/001041515814709310

Cardoso, F. H. (2006). A arte da política: a história que vivi. Rio de Janeiro, RJ: Civilização Brasileira.

Cardoso, F. H. (2015). Diários da Presidência 19951996. São Paulo, SP: Companhia das Letras.
Codato, A., \& P. Franz (2018). Ministros-técnicos e ministros-políticos nos governos do PSDB e do PT. Revista de Administração Pública, 52(5), 776796. Recuperado de https://doi.org/10.1590/00347612174301

D’Araujo, M. C. S., \& Ribeiro, G. L (2018). Trajetória socioeducacional dos ministros brasileiros na Nova República (1985-2014). Revista de Sociologia e Política, 26(65), 39-61. Recuperado de https://doi. org/10.1590/1678-987317266503

Inácio, M. (2013). Escogiendo ministros y formando políticos: los partidos en gabinetes multipartidistas. América Latina Hoy, 64, 41-66. Recuperado de https://doi.org/10.14201/alh.10231

Inglehart, R. (2015). The silent revolution: changing values and political styles. Nova Jersey, NJ: Princeton University Press.

Loureiro, M. R., \& Abrucio, F. L. (1999). Política e burocracia no presidencialismo brasileiro: $\mathrm{O}$ papel do Ministério da Fazenda no primeiro governo Fernando Henrique Cardoso. Revista Brasileira de Ciências Sociais, 14(41), 69-89. Recuperado de https://doi.org/10.1590/S0102-69091999000300005

Loureiro, M. R., Abrucio, F. L., \& Rosa, C. A. (1998). Radiografia da alta burocracia federal brasileira: o caso do Ministério da Fazenda. Revista do Serviço Público, 49(4), 46-82. Recuperado de https://doi. org/10.21874/rsp.v49i4.400

Martínez-Gallardo, C., \& Schleiter,P. (2015). Choosing whom to trust: agency risks and cabinet partisanship in presidential democracies. Comparative Political Studies, 48(2), 231-264. Recuperado de https://doi. org/10.1177/0010414014544361

Mauerber, A., Jr., \& Pereira, C. (2020). How valuable is a presidential cabinet? Measuring ministries' political attractiveness in Brazil. Latin American Politics and Society, 62(1), 25-45. Recuperado de https://doi.org/10.1017/lap.2019.44

Palotti, P. L. D. M., \& Cavalcante, P. L. C. (2018). Does one size fit all? An analysis of portfolio allocation in the Brazilian multiparty presidential system. Opinião Pública, 24(2), 427-455. Recuperado de https://doi. org/10.1590/1807-01912018242427

Palotti, P. L. D. M., \& Cavalcante, P. L. C. (2019). Estratégias de nomeações ministeriais: entre a 
política e as políticas públicas. Revista de Sociologia e Política, 27(70), e001. Recuperado de https://doi. org/10.1590/1678987319277001

Pereira, C., Praça, S., Batista, M., \& Lopes, F. (2015). A nomeação de secretários-executivos e o monitoramento da coalizão no presidencialismo brasileiro. In F. Lopes (Org.), Cargos de confiança no presidencialismo de coalizão brasileiro (pp. 139-164). Brasília, DF: IPEA.

Romano, G. (2019, fevereiro 18). Bolsonaro supera Geisel, Médici e Figueiredo em ministros militares. Veja. Recuperado de https://veja.abril. com.br/politica/bolsonaro-supera-geisel-medici-efigueiredo-em-ministros-militares/
Soares, G. A. D. (1973). Desigualdades eleitorais no Brasil. Revista de Ciência Política, 7(1), 25-48. Recuperado de https://bibliotecadigital.fgv.br/ojs/ index.php/rcp/article/view/59226

Souza, M. C. C. (2006). Federalismo no Brasil: aspectos político-institucionais (1930-1964). Revista Brasileira de Ciências Sociais, 21(61), 7-40. Recuperado de https://doi.org/10.1590/S010269092006000200002

Zucco, C., Jr., Batista, M., \& Power, T. J. (2019). Measuring portfolio salience using the BradleyTerry model: an illustration with data from Brazil. Research \& Politics, 6(1), 1-8. Recuperado de https:// doi.org/10.1177/2053168019832089

\section{Pedro Neiva}

https://orcid.org/0000-0002-4888-7515

Doutor em Ciência Política pelo Instituto Universitário de Pesquisas do Rio de Janeiro (IUPERJ); Professor Adjunto da Universidade de Brasília (UnB). E-mail: prneiva@gmail.com

\section{Taeko Hiroi}

https://orcid.org/0000-0003-0751-9342

Doutora em Ciência Política pela University of Pittsburgh; Professora do Departamento de Ciência Política na The University of Texas at El Paso. E-mail: thiroi@utep.edu 
RAP | A relação entre demanda e desempenho dos magistrados: investigação de um modelo funcional em forma de $U$ invertido

\section{APÊNDICE}

TABELA A NÚMERO DE MINISTROS “POLITICOS” NOS MINISTÉRIOS PRINCIPAIS

\begin{tabular}{|c|c|c|c|}
\hline Ministério & $\begin{array}{l}\text { Ministros } \\
\text { políticos (\%) }\end{array}$ & N & $\begin{array}{l}\text { Importância de acordo com os } \\
\text { parlamentares }\end{array}$ \\
\hline Cidades & 90,0 & 10 & 0,00 \\
\hline Agricultura & 87,5 & 24 & $-2,17$ \\
\hline Relações Institucionais & 85,7 & 14 & $-2,90$ \\
\hline Saúde & 80,8 & 26 & $-1,69$ \\
\hline Comunicações & 80,0 & 15 & $-2,75$ \\
\hline Desenvolvimento Agrário & 80,0 & 15 & $-3,98$ \\
\hline Integração/Desenv. Regional & 78,3 & 23 & $-2,17$ \\
\hline Secret.Geral da Presidência & 75,0 & 12 & $-3,06$ \\
\hline Educação & 73,9 & 23 & $-1,25$ \\
\hline Transportes & 73,9 & 23 & $-3,64$ \\
\hline Previdência & 72,7 & 22 & $-2,61$ \\
\hline Trabalho & 72,7 & 22 & $-2,33$ \\
\hline Defesa & 71,4 & 14 & $-3,22$ \\
\hline Direitos Humanos & 70,6 & 17 & $-4,36$ \\
\hline Justiça & 70,0 & 30 & $-2,45$ \\
\hline Casa (Gabinete) Civil & 68,2 & 22 & $-0,61$ \\
\hline Esportes & 66,7 & 15 & $-4,82$ \\
\hline Meio Ambiente & 64,7 & 17 & $-3,67$ \\
\hline Desenvolvimento Social & 64,3 & 14 & $-2,90$ \\
\hline Ciência e Tecnologia & 63,6 & 22 & $-2,17$ \\
\hline Turismo & 61,5 & 13 & $-4,35$ \\
\hline Planejamento & 57,1 & 21 & $-0,15$ \\
\hline Minas e Energia & 55,6 & 18 & $-1,40$ \\
\hline Indústria e Comércio & 55,0 & 20 & $-2,71$ \\
\hline Relações Exteriores & 47,1 & 17 & $-2,40$ \\
\hline Cultura & 43,5 & 23 & $-4,69$ \\
\hline Fazenda & 40,9 & 22 & $-0,24$ \\
\hline
\end{tabular}

Fonte: Elaborada pelos autores. 